\title{
Public Health Student Response to COVID-19
}

\author{
Kaelyn F. Burns ${ }^{1}$. Colten J. Strickland ${ }^{2}$ · Jennifer A. Horney ${ }^{3}$ ()
}

Published online: 19 August 2020

○) Springer Science+Business Media, LLC, part of Springer Nature 2020

\begin{abstract}
To understand the role public health students play in response to COVID-19 despite cuts in funding for graduate student emergency response programs (GSERPs), we reviewed the websites of the Association of Schools and Programs of Public Health, Council on Education in Public Health, and individual schools and programs to identify student participation in COVID-19 response activities. Thirty schools and programs of public health are supporting public health agencies in response to COVID-19, primarily through the provision of surge capacity $(n=20,66.7 \%)$, contact tracing $(n=19,63.3 \%)$, and training $(n=11,36.7 \%)$. The opportunity to participate in formal and informal applied public health experiences like practica, service-learning, and field placements can benefit both public health students and agency partners. Although recent publications have identified gaps in academic public health response to COVID-19, in part due to the cessation of funding for workforce development and other university-based programs in public health preparedness, schools and programs of public health continue to support public health agencies. Future funding should explicitly link public health students to applied public health activities in ways that can be measured to document impacts on public health emergency response and the future public health workforce.
\end{abstract}

Keywords COVID-19 $\cdot$ Public health students $\cdot$ Public health workforce $\cdot$ Surge capacity $\cdot$ Public health preparedness

\section{Introduction}

The size of the U.S. public health workforce has been declining at the state and local levels over the past several decades $[1,2]$. Due in part to the 2008 economic downturn, the public health workforce declined by more than 50,000 full-time employees between 2008 and 2016 [1]. In addition to these declines, $22 \%$ of current public health employees are planning to retire by 2023 , leading to concerns about the stability of the public health workforce for years to come [3]. One approach to addressing existing workforce shortages and fueling the future workforce pipeline has been through the development of explicit linkages between academic institutions and public health agencies $[4,5]$. These linkages can be

Jennifer A. Horney

horney@udel.edu

1 Human Nutrition, University of Delaware, Newark, DE, USA

2 Epidemiology Program, University of Delaware, Newark, DE, USA

3 Epidemiology Program, University of Delaware, 100 Discovery Blvd, Room 731, Newark, DE 19713, USA mutually beneficial, allowing students to gain experience in public health practice while contributing to the growth and professionalization of the public health workforce $[5,6]$. Such linkages have been shown to increase the likelihood that students enter careers in governmental public health, where gaps are the greatest [5].

Novel recruitment strategies are needed to build the public health workforce, particularly in the area of epidemiology. Assessments by national organizations such as the Association of Public Health Laboratories (APHL), Association of State and Territorial Health Officials (ASTHO), Council of State and Territorial Epidemiologists (CSTE), and National Association of County and City Health Officials (NACCHO) have shown that there are approximately 8,000 epidemiology positions in governmental public health across the U.S., which represents only $3 \%$ of the entire public health workforce [7]. In addition, little is known about the epidemiology-specific education and training of the current public health workforce [8]. In many public health agencies, epidemiology functions including disease surveillance, study design, data collection and analysis, and designing disease control methods are carried out by public health nurses or environmental health specialists [9]. One-third of 
epidemiology staff in small and medium jurisdictions lack formal academic training in epidemiology, limiting the overall epidemiologic capacity of the public health system $[8,9]$.

Graduate student emergency response programs (GSERPs) are one way that collaboration between academia and public health practice can occur. GSERPs were initially formed in the early and mid 2000s at Schools of Public Health and supported with funding from the Centers for Disease Control and Prevention (CDC) through the Centers for Public Health Preparedness and the Preparedness and Emergency Response Learning Center grants. The goal of these Centers was to improve the capacity of the U.S. public health workforce to prepare for and respond to terrorism and other emerging public health threats through competency-based workforce development [10]. GSERPs were one approach used by these Centers to meet this goal [6]. Although the specifics of their organization varied, GSERPs recruited mostly graduate level public health students to provide surge capacity to state and local health departments while also providing students with applied public health experience and activity-specific training and strengthening partnerships between universities and public health agencies $[5,6]$. However, by 2014 funding for these programs had mostly ended and many GSERPs were discontinued [11, 12]. This loss of preparedness funding to academic institutions had several consequences relevant to facing the current public health threat from COVID-19. Recent graduates from schools of public health may have chosen careers outside of public health practice in general or the shrinking field of public health preparedness and response specifically, potentially diminishing public health emergency preparedness and response capacity and expertise. Additionally, without the types of explicit linkages between academic public health programs and public health practice, academic programs may have limited capacity to support public health departments appropriately during a crisis such as a pandemic, lending support to the assertion that a shortage of 250,000 public health workers was no way to fight to the COVID-19 pandemic [4, 13].

With regard to the role public health students can play in response to COVID-19, the accrediting body for Schools and Programs of Public Health, the Council on Education in Public Health (CEPH), supports "applied practice experiences that provide capacity to the public health community that is managing and responding to the COVID-19 crisis" [14]. Despite limitations due to state-level stay-at-home policies and travel restrictions, University closures, host-site policies restricting students from working on-site, and other challenges to students' participation in COVID-related fieldwork [15], as of July 31st, 2020, 30 public health schools and programs had provided support for the public health response to COVID-19. In the short term, this student support assists public health's ongoing response to COVID-19 through the provision of surge capacity. In the longer term, it may also pique student's interest in a career in applied public health.

\section{Methods}

The websites of the Association of Schools and Programs of Public Health (ASPPH) and CEPH $[14,16]$ were reviewed to document any published reports regarding students within schools or programs of public health participating in surge response activities related to COVID-19. On the ASPPH website, the reports were found within the "Preparedness $\&$ Response" section of the website. On the CEPH website, the reports were found within the "COVID-19 Related Updates" section of the website. To account for the contributions of new public health programs that have not yet begun or completed the accreditation application process and would not yet be represented on the ASPPH or CEPH websites, a Google search using the keywords "public health students' response to COVID-19" was used. All data collected were cross-referenced on the respective school's websites to confirm the information listed on the ASPPH and CEPH websites were accurate. Data were collected from May 26th, 2020 through July 31st, 2020. Multiple searches took place in this time frame to collect any newly published reports. All data were recorded in a Microsoft Excel (Redmond, WA) spreadsheet and inductive coding was used to identify themes to categorize student activities.

\section{Results}

A total of 30 schools and programs reported on student surge response activities related to COVID-19. See Table 1 for a list of all identified schools and programs. Most schools and programs that reported activities ( 25 of $30 ; 83.33 \%$ ) were accredited schools or programs of public health. Twenty of 30 schools $(66.67 \%)$ have a school of public health and 5 of 30 schools $(16.67 \%)$ have a program of public health. Five of 30 schools (16.67\%) do not have either a school or program of public health but were included in this review given their student's involvement in COVID-19 related activities. Three themes were identified among the reported student surge response activities.

\section{Contact Training}

Nineteen of the 30 schools and programs $(63.33 \%)$ reported students being trained as COVID-19 contact tracers. Contact tracing, and the subsequent identification and isolation or quarantine of ill or exposed contacts, is a public health control measure used to reduce the spread of communicable 
Table 1 Public health student activities by theme across the U.S as of July 31, 2020

\begin{tabular}{|c|c|}
\hline Identified themes of student activities & Schools Involved (Total $=30$ ) \\
\hline $\begin{array}{l}\text { Providing Surge Capacity for State and Local Health } \\
\text { Departments } \\
\mathrm{N}=20\end{array}$ & $\begin{array}{l}\text { Boston University School of Public Health } \\
\text { Florida International University College of Public Health and Social Work } \\
\text { Harvard University School of Public Health } \\
\text { Massachusetts College of Pharmacy and Health Sciences* } \\
\text { Northeastern University Public Health Program } \\
\text { Regis College* } \\
\text { Rutgers University School of Public Health } \\
\text { Simmons University* } \\
\text { Tufts University School of Medicine Public Health Program } \\
\text { Tulane University School of Public Health and Tropical Medicine } \\
\text { University at Buffalo - SUNY School of Public Health and Health Professions } \\
\text { University of Albany School of Public Health } \\
\text { University of Arizona College of Public Health } \\
\text { University of Florida College of Public Health and Health Professions } \\
\text { University of Massachusetts Amherst School of Public Health and Health Sciences } \\
\text { University of Massachusetts Lowell* } \\
\text { University of Nebraska Medical Center College of Public Health } \\
\text { University of North Texas Health Science Center School of Public Health } \\
\text { University of Washington School of Public Health } \\
\text { Virginia Tech Public Health Program }\end{array}$ \\
\hline $\begin{array}{l}\text { Training and Education } \\
\mathrm{N}=11\end{array}$ & $\begin{array}{l}\text { Boston University School of Public Health } \\
\text { Colorado State University* } \\
\text { Columbia University School of Public Health } \\
\text { George Mason University Public Health Program } \\
\text { Harvard University School of Public Health } \\
\text { Oregon State University College of Public Health and Human Sciences } \\
\text { Tulane University School of Public Health and Tropical Medicine } \\
\text { University at Buffalo - SUNY School of Public Health and Health Professions } \\
\text { University of Arizona College of Public Health } \\
\text { University of Iowa College of Public Health } \\
\text { University of Massachusetts Amherst School of Public Health and Health Sciences }\end{array}$ \\
\hline
\end{tabular}


Table 1 (continued)

\begin{tabular}{|c|c|}
\hline Identified themes of student activities & Schools Involved (Total $=30$ ) \\
\hline \multirow{19}{*}{$\begin{array}{l}\text { Contact Tracing } \\
\mathrm{N}=19\end{array}$} & Boston University School of Public Health \\
\hline & Colorado State University* \\
\hline & Harvard University School of Public Health \\
\hline & Massachusetts College of Pharmacy and Health Sciences* \\
\hline & North Dakota State University Public Health Program \\
\hline & Northeastern University Public Health Program \\
\hline & Regis College* \\
\hline & Simmons University* \\
\hline & Tufts University School of Public Health and Tropical Medicine \\
\hline & University of Albany School of Public Health \\
\hline & University of Arizona College of Public Health \\
\hline & University of Colorado Denver School of Public Health \\
\hline & University of Kentucky College of Public Health \\
\hline & University of Massachusetts Amherst School of Public Health \\
\hline & University of Massachusetts Lowell* \\
\hline & University of Nebraska Medical Center College of Public Health \\
\hline & University of North Texas Health Science Center School of Public Health \\
\hline & University of South Florida College of Public Health \\
\hline & Yale University School of Public Health \\
\hline
\end{tabular}

*Not an accredited public health school or program

diseases [17]. It is particularly important for the control of community spread of COVID-19 since no treatment or vaccine currently exists. In all cases, public health students were trained to connect with contacts of confirmed cases of COVID-19 via telephone to provide guidance related to appropriate self-quarantine procedures. Two of the 19 schools (10.53\%) reported students provided additional assistance, including daily follow-up with case patient contacts to collect health-monitoring data such as symptom reporting.

\section{Training and Education}

Students played several roles to support needs related to expanded community-based training and health education programs. Eleven of the 30 schools (36.67\%) reported their students participated in efforts to educate their local community, with many unique programs described. At three of the 11 schools (27.27\%), public health students collaborated with local health departments to keep their community up to date on safety recommendations regarding COVID-19. Those students produced educational materials and created infographics that raised awareness and conveyed best practices to prevent the spread of COVID-19 such as social distancing and hand washing. To keep diverse communities informed, bilingual students from a handful of public health programs (3 of $11 ; 27.27 \%$ ) collaborated with their local public health agency to translate COVID-19 informational materials into as many as 11 different languages.

\section{Providing Surge Capacity for State and Local Health Departments}

Most of the reported student surge capacity activities included providing direct assistance to state and local public health departments. Twenty of the 30 schools (66.67\%) reported students volunteered with health departments. Students from seven of those 20 schools (35.0\%) worked in public health call centers to provide current information about COVID-19 to the public. Two of the twenty schools (10.0\%) reported students supported the local health department by assisting at mobile diagnostic testing sites in underserved communities where in addition to testing, students were able to apply knowledge learned from public health courses by providing information to individuals about best practices for mitigating the spread of the virus including the importance 
of social distancing and risk perception. Students at one school (1 of 20; 5.0\%) assisted the health department by performing in-person wellness checks on vulnerable populations, carrying out health equity research related to COVID19 , and conducting data analysis.

\section{Discussion}

The public health workforce is insufficient to meet the current and future needs of the U.S. in many areas including public health emergency preparedness [2, 12]. For many public health agencies, the COVID-19 pandemic has exposed gaps in capacity that are due, in part, to the loss of emergency preparedness funding for both public health departments and their academic partners [4, 18]. A welltrained and greatly expanded public health workforce is needed to provide health education and outreach to vulnerable communities, to support testing, and to expand contact tracing in response to COVID-19. To develop a public health workforce sufficient to respond to public health emergencies, efforts to support workforce capacity and development are needed [19].

Public health students can provide some of the needed surge capacity to local and state public health agencies who are currently understaffed to adequately respond to COVID19. While students are able to provide personnel, it is not known the extent to which students learn relevant skills to provide meaningful surge capacity through their coursework. To address the scale and scope of a global pandemic, both formal and informal programs that support and facilitate student engagement are needed. These include standard programs that are part of the public health curriculum, like required practica, as well as innovative programs like GSERPs, service-learning, field placements, and potentially even new opportunities for national service or early degree completion [20, 21]. In addition to providing surge capacity, students who have the opportunity to participate in these types of programs may be more likely to choose a career in governmental public health [5], helping to address documented public health workforce shortages now and in the future.

This study has several important limitations. Academic public health programs are growing rapidly and not all programs are represented by ASPPH or CEPH. Programs that provided surge capacity support that are not yet accredited or are applying for accreditation may have been less likely to be included in the data since ASPPH and CEPH have proactively requested schools and programs share press releases and other information about their participation in the COVID-19 response. Since nearly all higher education institutions are closed and operating remotely, not all activities may be documented in real time. Lastly, no effort was made to follow-up with schools to ensure the data collected were complete.

\section{Conclusions}

Graduate, and increasingly undergraduate, students in schools and programs of public health can potentially provide necessary surge capacity in response to the COVID19 pandemic to understaffed and underfunded governmental public health agencies. In addition to providing surge capacity, the experience gained by students can contribute to ensuring that the next generation of the workforce is trained for the next pandemic or public health emergency. However, due to reductions - as well as changes in focus - of public health emergency preparedness and response funding, students enrolled in schools and programs of public health are likely underutilized and their efforts unsustainable without renewed funding and the revitalization of more explicit linkages between academia and practice [4].

Funding for GSERPs and similar programs is a cost-effective way to provide student surge capacity for responses to public health crises such as COVID-19, while simultaneously providing students with work experience in governmental public health and the opportunity to build professional networks among public health practitioners. The CDC and other funders should again consider expanded support and guidance for GSERPs to fuel the applied public health workforce pipeline and ensure that it is ready to respond to future public health emergencies.

Funding No funding was received for this work.

\section{Compliance with Ethical Standards}

Conflict of interest The authors have no financial or other conflicts of interest.

\section{References}

1. Leider, J. P., Coronado, F., Beck, A. J., \& Harper, E. (2018). Reconciling supply and demand for state and local public health staff in an era of retiring baby boomers. American Journal of Preventive Medicine, 54(3), 334-340.

2. Associations of Schools of Public Health. (2008). ASPH Policy Brief: Confronting the Public Health Workforce Crisis. Washington DC: Associations of Schools of Public Health.

3. Sellers, K., Leider, J. P., Gould, E., Castrucci, B. C., Beck, A., Bogaert, K., et al. (2019). The State of the US Governmental Public Health Workforce, 2014-2017. American Journal of Public Health, 109(5), 674-680.

4. McCoy, S. I., \& MacDonald, P. D. M. (2020). Need to Amplify health security? Fuse Academia and Practice. Public Health Report, $00(0), 1-4$. 
5. Horney, J. A., Davis, M. K., Ricchetti-Masterson, K. L., \& MacDonald, P. D. (2014). Fueling the public health workforce pipeline through student surge capacity response teams. Journal of Community Health, 39(1), 35-39.

6. Centers for Public Health Preparedness. (2005). Graduate Student Epidemiology Response Programs At Centers For Public Health Preparedness.

7. Beck, A. J., Boulton, M. L., \& Coronado, F. (2014). Enumeration of the governmental public health workforce, 2014. American Journal of Preventive Medicine, 47(5 Suppl 3), S306-S313.

8. O'Keefe, K. A., Shafir, S. C., \& Shoaf, K. I. (2013). Local health department epidemiologic capacity: a stratified cross-sectional assessment describing the quantity, education, training, and perceived competencies of epidemiologic staff. Frontiers in Public Health, 1, 64.

9. Moehrle, C. (2008). Who conducts epidemiology activities in local public health departments? Public Health Report, 123(Suppl 1), 6-7.

10. Richmond, A. L., Sobelson, R. K., \& Cioffi, J. P. (2014). Preparedness and Emergency Response Learning Centers: Supporting the workforce for national health security. Journal of Public Health Management and Practice, 20(Suppl 5), S7-S16.

11. Baker, E. L., Lichtveld, M. Y., \& MacDonald, P. D. (2010). The Centers for Public Health Preparedness Program: From vision to reality. Public Health Report, 125(Suppl 5), 4-7.

12. Watson, C. R., Watson, M., \& Sell, T. K. (2017). Public Health Preparedness Funding: Key Programs and Trends From 2001 to 2017. American Journal of Public Health, 107(S2), S165-S167.

13. Wilson, R. T., Troisi, C. L., \& Gary-Webb, T. L. (2020). A deficit of more than 250,000 public health workers is no way to fight Covid-19. Retrieved June 25, 2020 from https://www.statnews. com/2020/04/05/deficit-public-health-workers-no-way-to-fight -covid-19/.
14. Council on Education for Public Health. (2020). COVID-19 Related Updates. Retrieved June 25, 2020 from https://ceph.org/ covid19/?fbclid=IwAR10UBulrUW7hjQkaABLUhHBmVQFxWDxLiH7uMtNEKT-nwH0fbJhpsFW_OM.

15. Centers for Disease Control and Prevention. (2020). Considerations for Institutions of Higher Education. Retrieved June 25, 2020 from https://www.cdc.gov/coronavirus/2019-ncov/community/ colleges-universities/considerations.html.

16. Assocations of Schools and Programs of Public Health. (2020). ASPPH Member COVID-19 Coverage. /. Retrieved June 25, 2020 from https://www.aspph.org/connect/covid-19-member-coverage.

17. Eames, K. T., \& Keeling, M. J. (2003). Contact tracing and disease control. Proceedings of Biological Sciene, 270(1533), 2565-2571.

18. Levi, J., Segal, L., \& Laurent, St, R. (2012). Investing in America's Health: A State-By-State Look at Public Health Health Funding and Key Health Facts.

19. National Academies of Sciences, Engineering, and Medicine. (2020). Evidence-Based Practice for Public Health Emergency Preparedness and Response. Washington, DC: The National Academies Press.

20. Bauchner, H., \& Sharfstein, J. (2020). A Bold Response to the COVID-19 Pandemic: Medical Students, National Service, and Public Health. JAMA.

21. Bogossian, F., McKenna, L., \& Levett-Jones, T. (2020). Mobilising the nursing student workforce in COVID-19: The value proposition. Collegian (Royal College of Nursing, Australia), 27, $147-149$.

Publisher's Note Springer Nature remains neutral with regard to jurisdictional claims in published maps and institutional affiliations. 